\title{
Phonemic Comparison of English and Punjabi
}

\author{
Muhammad Nadeem Chohan ${ }^{1} \&$ Maria Isabel Maldonado García ${ }^{1}$ \\ ${ }^{1}$ Department of English Language and Literature, University of Management and Technology, Lahore, Pakistan \\ Correspondence: Muhammad Nadeem Chohan, Department of English Language and Literature, University of \\ Management and Technology, Lahore, Pakistan. E-mail: nadeemchuhan@gmail.com
}

Received: May 3, 2019 Accepted: June 5, 2019 Online Published: July 12, 2019

doi:10.5539/ijel.v9n4p347 URL: https://doi.org/10.5539/ijel.v9n4p347

\begin{abstract}
English and Punjabi are languages which do not belong to the same families of languages. English is one of the West Germanic languages whereas; Punjabi is a part of the Indo-Aryan family. Punjabi is spoken by various nations on the globe, especially Pakistan and its province Punjab as well as in Indian Panjab. Both English and Punjabi manifest themselves through various dialects on the basis of diversified geographical areas. English is used as the first language by $379,007,140$ speakers and further $753,359,540$ speakers use it as a second language in more than 104 nations. So, the total speakers of English around the globe are 1,132,366,680 (Ethnologue, 2019). The importance of Punjabi cannot be denied being the 10th most widely used language on the globe (Ghai \& Singh, 2013). According to Ethnologue (2019), the total number of Punjabi speakers is $125,326,840$. In Pakistan, it is the language of the majority of the people residing in the most populous province of Pakistan, Punjab. It is among twenty-two languages that have obtained official status. Unfortunately, no considerable work has been done on its phonology. This study is an attempt to describe the phonemic differences between English and Punjabi by using the theoretical framework of the Levenshtein algorithm. The index of differences and similarities is determined through the inventories of both languages. The inventories are used as data in this research paper. The Levenshtein algorithm (Levenshtein, 1965) is used to analyse the inventories to calculate the ratio of differences and similarities. The outcome of the current research shows that both English and Punjabi have a phonemic similarity level of $56.25 \%$ whereas the index of difference is $43.75 \%$.
\end{abstract}

Keywords: Punjabi, Majhi, dialect, phonemic differences, phonetics, Levenshtein algorithm, English

\section{Introduction}

English is one of the West Germanic languages (Dufour, 2017). Its name comes from Angles, a Germanic tribe (Pyles \& Algeo, 1993). This tribe migrated towards the various areas of Great Britain, the area was named as England (Hogg \& Burchfield, 1992). The Germanic family of languages is vast. Some of its languages are English, Frisian, as well as Dutch and German and others. The vocabulary of English is greatly influenced by some other North Germanic languages, along with Latin and French (Dalton, 2011). The English language developed and progressed over the course of more than 1,400 years. The West Germanic dialects came to England around the 5th century AD brought by settlers of Anglo-Saxon origin. These earliest forms of English are jointly called Old English. At that point, Middle English began with the Norman success of England. It was the era in which it was considerably affected by the French. Afterwards, in the late fifteenth century around the same time as the arrival of the printing press in the city of London English developed into an early modern form. The impact of the British Empire was shifted by the beginning of the Great Vowel Shift and the printing of the King James Bible. Present-day English spread the world over from 17th to the middle of the 20th century through various means of technology and especially after the rising of the USA as an international power. English has become the most used international language for various scopes of life like international trade, media, science, law, etc. (Algeo \& Butcher, 2013). Around 379,007,140 individuals communicate in English as their first language and a further $753,359,540$ people use it as a foreign tongue in more than 100 nations around the world (Ethnologue, 2019)

A mixture of two words, "Punj" and "Aab" meaning as "five" and "water" respectively creates "Punjabi" with the meaning of five rivers. The region of Punjab spreads in Pakistan and India and their language Punjabi is a language spoken in both countries (Masica, 1993). A great majority of the people of Pakistan speak Punjabi as a first language. In India, it is an official language with other 21 official languages (Ethnologue, 2016). According to CIA Factbook, the colloquial Punjabi language can be divided into three groups: Central, the Majhi dialect 
spoken in Lahore and Amritsar and it makes the literary language; the Dogri in northern Punjab; and the western dialects that gradually change into Lahnda (Campbell, 1991). According to Ethnologue2015, Majhi is the purest form of Punjabi. In addition to Pakistan and India, the speakers of Punjabi are also found in Canada, East Africa, and the United Kingdom. Almost forty-five million speakers use Punjabi either as their first or second language (Bhatia, 1993). There is variation among the dialects of Punjabi which led it to be classified into four groups; Eastern dialects, Dogri, Majhi and Western dialects (Shackle, 1970). According to Sir Richard Temple, the language was classified into several major dialectal varieties: Multani Majhi, Pahari and Potohari (1883). On the other hand, Campbell divided the Punjabi language into three groups: Central, the Majhi dialect spoken in central Punjab and it makes the literary language; the Dogri in northern Punjab; and the western dialects that gradually change into Lahnda.

\subsection{Background}

Punjabi is an official language in India with other 21 languages which enjoy official status in India. In Indian Panjab, the language is the first official language and Chandigarh. It is also official in Haryana, Delhi and Himachal Pradesh, however, is the second official language. Similarly, it enjoys the status of provincial language in Pakistan and is the official language of Punjab (Kaur, 2012). Punjabi is considered to be tonal. It is due to the fact that it uses tones for the purpose of discriminating words that would otherwise be the same (Ghai \& Singh, 2012). In the Punjabi language, three tones, mid-rising-falling, high-rising-falling and low rising, have been identified as main tones. It is the proper use of tone that makes Punjabi speakers able to differentiate among the words which can appear exactly the same to the speakers of languages which do not speak a tonal language. It is highly challenging for the learners, who wish to learn Punjabi as their second language, to achieve mastery of the tonal system of the language. The change of tone can change the pragmatics of the language (Brinton \& Traugott, 2005). Another factor to have in mind in that the dialect is very significant, important as well as a complicated element of a speaker's idiosyncrasy. Dialects are defined as the varieties of a language for the purpose of this study. When comparing two varieties of the same language, both these varieties do have the structural overlap that causes the mutual intelligibility. The script of these varieties may either be convertible or the same. The variations found between the two dialects at acoustic and phonemic levels can be as accents (Chen et al., 2014; Purnell, 1999).

\subsection{The Rationale of the Study}

This study investigates phonemic differences and similarities between English and Punjabi. The chief rationale of the study intends to uncover these. This purpose is achieved by calculating the similarity index between these linguistic systems. If we take the example of Spanish and Portuguese, both descend from the same language as they have $89 \%$ of the similarity index (Ethnologue, 2016). These differences are very important to know as they set these two linguistic systems apart. It is what makes linguistic systems different from each other and standing in their own individual way. Linguistic systems can be distinguished through the analysis of their grammar, lexicon, phonology and some other structural features (Myers-Scotton, 2005).

\subsection{Statement of the Problem}

English has been studied phonemically in various researches, and Punjabi is no exception. However, the work on Punjabi phonology is far less than that of English. The phonemic characteristics of Punjabi had been described by different researchers (Karamat, 2012; Dua, Aggarwal, Kadyan, \& Dua, 2012; Goyal \& Lehal, 2008). Nevertheless, no research has been found that provides the description of the phonemic similarities and the differences between English and Punjabi. That's why the similarity index between both phonemic systems is not known. The present research article aims to calculate the phonemic similarities and differences between English and Punjabi. The purpose of this calculation is to find those sounds of English that are not present in the Punjabi phonemic system and those sounds of Punjabi that are not present in the English phonemic system and can cause difficulties to the learners of each language.

\subsection{Significance of the Study}

English is spoken by a large number of speakers as their second language throughout the world including Pakistan. Many speakers from all over the world, in addition to their mother tongue, use English as well; the same situation is present in Pakistan, where English is an official language. A large percentage of Pakistani speakers who speak Punjabi as a native language also use English as it is an official foreign language (Maldonado Garcia, 2018). For this reason and because English is the language of science, technology, education and development many Punjabis try to learn it. The research's objective is to analyse the differences in phonemic variations between Punjabi and English, as it will help the Punjabi speakers to learn English as their L2 through the manifestation of positive and negative transfer between these two languages. 
Modern English dialects can be viewed as the extension of the dialectical territories which settled themselves in the era of Old English. The colloquial partition of the smaller district of England into a northern, focal and southern setting has been held in the present era. The semantic investigation of the English dialect returns to the 19th century when, as an off-spin of Indo-European examinations, the investigation into significant European dialects was extensively created. Alexander Ellis is an authentic figure in the field of English dialectology, pursued fairly later by Joseph Wright (late nineteenth and mid-twentieth century).

\section{Literature Review}

Phonology is the study of the sounds in a particular language and it explains the sounds system of a particular language. It also tells how sounds are combined into different words. And describes why certain phonetic are essential to identify a word (Davenport \& Hannahs, 2013; Clark \& Yallop, 2011; Giegerich, 1992). In a phonetic inventory the sounds, found in a language are explained and described, regardless of the fact, either these sounds are articulated accurately or not within a particular language. It is the study of the human languages sound systems. It is the study of the functions of speech sounds. The term is used both for the discipline and for the object of inquiry; we talk of phonology as a field of study, parallel to politics, but as with the term 'politics', we also use the word 'phonology' to refer to the sound systems under investigation, as in the phrase 'Vowel harmony occurs in the phonology of Hungarian.' The distinction and relation between phonology and phonetics are controversial (Carr, 2008). Every language has its own phonology which comprises its whole sound system explaining in detail the consonants and the vowels of that language (Roach, 2009).

The phoneme is a meaningful sound that will change one word into another word. The difference of only one sound can make two different. For example, in two the words "PAT" and "BAT" the difference is only one sound and both the other two sounds are the same in these words. Only $/ \mathrm{p} /$ and $/ \mathrm{b} /$ are different in these words. It means that $/ \mathrm{p} /$ in PAT and $/ \mathrm{b} /$ in BAT are two different phonemes (Gimson, 1980).

According to Lan Maddieson (1984), a phonetic inventory could explain all speech sounds, regardless of this, the sounds are produced correctly or not in a specific language or a phonetic inventory is a key which explains the different phonemic sounds in a specifically given language where the set of consonants and vowels are called consonantal and vocalic inventories respectively.

Consonants are the sounds in the production of which there is complete closure or the narrowing of the air passage in the mouth cavity by bringing different articulators closing to gather. Roach (2009) explains different types of consonants in following ways; there are many types of consonants and the common thing in all is that they obstruct the flow of air in vocal or nasal tract completely or partially. These consonant sounds are categorised into plosives, fricatives, affricates, nasals, and lateral and semivowels/approximants, on the basis of their manner of articulation. On the other hand, they are categorized into bilabial, labiodentals, dental, alveolar, palatal and glottal on the basis of their places of articulation (Roach, 2009).

Sundara (2005) conducted a study to compare Canadian English (CE) and Canadian French (CF) in order to give the description of coronal stops. The analysis of this research showed that the stops of CF and CE have different voice onset time (VOT) as well as a place of articulation. The stops in both these languages have relatively different burst intensity and spectral shape of the burst. They are different in their mean frequency, kurtosis, and standard deviation. The results of the study were interpreted from several other languages on the basis of acoustic and articulatory phonetics.

A study of Renata Gregova (2010) which analysed the consonant systems of English and Slovak revealed that Solvak has a rich system of consonant clusters that cannot be treated as complex sounds and cannot be accounted for as separate phonemes.

Javed (2013) from Roorkee Engineering \& Management Technology Institute, India, in the research article titled "Arabic and English Phonetics: A Comparative Study" explained differences and similarities between English and Arabic, in term of vowel and consonant sound, to accommodate the learners of both the language with respect to learn correct pronunciation. He tried to describe, classify and differentiate the consonants and vowel sounds found in both the languages. The comparison was made to find out the similarities and differences found in both linguistic systems in term of their phonology. The main purpose of this research was to provide help to those people who want the correct pronunciation of these languages. This type of comparison between the sounds of English and Arabic is of great help for the learners of the second language.

In terms of the phonemic comparison of Pakistani languages and English, a significant study is that of Ghani Rahman (2016) where he compared the phonemic inventories of English and Pashto, a language of Khyber Pakhtoonkwa, one of the provinces of Pakistan. The study found that there is similarity in terms of place and 
manner of articulation between both languages. The gap of this study lies on the fact that phonemic comparison of the consonants of English and Punjabi has not been studied, so the present research will explain the differences and similarities between English and Punjabi to fill in the gap.

In this regard, orthographically there are 21 consonant letters in the English language which are B, C, D, F, G, H, J, K, L, M, N, P, Q, R, S, T, V, W, X, Y, Z. These Consonants letters have 24 corresponding sounds which are given in Figure 1, these sounds have friction or closure during the course of their production, most of them use the position of the tongue against the lips, teeth and roof of the mouth. In the light of their manner and places of articulation, they are divided into various categories Consonants may be voiced or unvoiced depending on the vibration of the vocal cords during their production (Roach, 2010). The English language consonant inventory is as follows:

\begin{tabular}{|c|c|c|c|c|c|c|c|c|c|}
\hline & & \multicolumn{8}{|c|}{ PLACE OF ARTICULATION } \\
\hline & & Bilabial & Labiodental & Dental & Alveolar & Post-alveolar & Palatal & Velar & Glottal \\
\hline \multirow{6}{*}{ 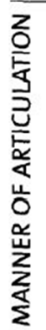 } & Plosive & $\mathrm{p} \mathrm{b}$ & & & $t d$ & & & $\mathrm{k} \mathrm{g}$ & \\
\hline & Fricative & & f $v$ & $\theta \partial$ & s z & $\int 3$ & & & $\mathrm{~h}$ \\
\hline & Affricate & & & & & if $d 3$ & & & \\
\hline & Nasal & $\mathrm{m}$ & & & $\mathrm{n}$ & & & $\eta$ & \\
\hline & Lateral approximant & & & & 1 & & & & \\
\hline & Approximant & w & & & & $\mathbf{r}$ & $\mathbf{j}$ & & \\
\hline
\end{tabular}

Figure 1. English inventory by Roach (2010)

Punjabi and Hindi are similar in terms of their phonologies but their script, way of writing alphabets and historical features are different from each other. Even the pronunciation varies on the basis of geographical changes within Pakistan. The pronunciation of Pakistani Punjabi varies than that of the Punjabi in India. Punjabi is a very rich linguistics variety loaded with a vast variety of sounds. These sounds may have different acoustic, segmental and super-segmental features like duration, quality, and nasalization. The differentiation among these feature makes them different from each other. The tone is considered very important and significant element in the Punjabi language. It is both phonemic and segmental in function. These features bring variation in the pitch that creates different shades of meanings of a single word which has the same vowel and consonant pattern (Karamat, 2012). Another very significant feature in the Punjabi language is nasalization by the Punjabi speakers. It is considered very important but its level of understandability is very low among Punjabi speakers. The oral sounds are produced with the configuration of the oral and nasal tract. But during the production of the nasal vowels, the nasal tract is completely closed and the velopharyngeal port is open (Zahid, 2010).

Grewal (2008) tried to discover the history of Punjabi, starting from Rigveda and the influence of different administrative changes and influences on the lifestyle of five Doabs. He also investigated the emerging of new communities and societies under the influences of these invaders. He also shows the development of new dialect.

Karamat (2012) in her research "The Phonemic Inventory of Punjabi" tried to make an inventory of Punjabi spoken in Lahore and its surrounding areas where the Mahji dialect of Punjabi is spoken. For this purpose, she gave various references to already available inventories of Punjabi. Punjabi possesses a large number of regional dialects which are spoken in both India as well as in Pakistan. According to Karamat Punjabi system of sounds involves five distinctive tongue positions: labial, dental, retroflex, palatal and velar. 


\begin{tabular}{|c|c|c|c|c|c|c|c|c|}
\hline & Bilabial & Labiodental & Dental & Alveolar & Retroflex & Palatal & Velar & Glotal \\
\hline \multirow[t]{3}{*}{ Plosive } & $\mathrm{p}$ & & $\mathrm{t}$ & & $\mathrm{t}$ & $t s$ & $\mathrm{k}$ & \\
\hline & $\mathrm{p}^{\mathrm{h}}$ & & $t^{h}$ & & $t^{h}$ & $t \int^{h}$ & $\mathrm{k}^{\mathrm{h}}$ & \\
\hline & $\mathrm{b}$ & & d & & $\mathrm{d}$ & d3 & $g$ & \\
\hline Nasal & $\mathrm{m}$ & & & $\mathrm{n}$ & $\eta$ & & $\mathrm{n}$ & \\
\hline \multirow[t]{2}{*}{ Fricative } & & $\mathrm{f}$ & & $\mathrm{s}$ & & $S$ & $x$ & $\mathrm{~h}$ \\
\hline & & $\mathrm{v}$ & & $z$ & & & $\gamma$ & \\
\hline Trill & & & & $\mathrm{r}$ & & & & \\
\hline Flap & & & & & $r$ & & & \\
\hline $\begin{array}{l}\text { Approxi- } \\
\text { mate }\end{array}$ & & & & 1 & $l$ & j & & \\
\hline
\end{tabular}

Figure 2. The consonant inventory of Punjabi language (Mahji dialect)

Gooskens and Schneider (2016) state that we may divide a word into two parts to calculate the word similarity. The "orthographic" part is closer to the real sounds while employing comparison on a character level. The separate encoding does not have any effect on the outcome. The "phonetic" part tries to obtain the benefit of the phonetic characteristics of separate sounds for the collection of similarity index. The classification of the language appeals to a definite structure of features regarding sound system; phonemic inventory, rhythmic patterns and prosodic structures.

Although every single lexical item is presented with only one symbolic representation, this single representation is always used to represent the lexical item on various levels of abstractions. Among this interpretation of the lexical items the most significant, fundamental and obvious interpretation is its phonetic interpretation which is called transcription. It throws light on the phonetic arrangement and realization of a particular word. The phonetic similarity may be deduced from a comparative perspective. Even similar transcription of the words on the least formal level of transcription may have differences. The words sharing even the same transcription will not be identical in term of their phonetics if they belong to two different languages. Symbols are assigned different values in different transcriptions. The difference can be measured between the different phonetic representations different cognate's items or linguistic varieties by using some distinct metric (Levenshtein, 1965). Phonological information of a lexical item is encoded by phonetic transcription of that particular item. The differences in the phonetic representation of the words within a single language represent minimally the lexical semantic contrast in the relational set. Phonetic transcription provides a complete set of the phonetic detail of a lexical item; it also gives the phonological contrast in comparison of the other lexical items. Spoken dictionaries are the deliberate examples of this, these dictionaries also provide the phonetic addition as well as the allophonic variation of the given lexical items in term of their phonetics. Schepens et al. (2013) tried to measure the boundaries among different levels of abstractions in term of phonemic and phonetic interchangeably. The phonetic transcriptions hold the position of the fundamental data in databases, it makes possible to compare and identify the cognates and their forms. Many differences and similarities may be missed on account of being over-focused on a particular field. Mostly these fields are not considered to be relevant in this contrast. On the other hand, it can be of much importance in the study of cross-linguistic patterns and its understanding (Hard castle \& Beck, 2005).

The most important thing here is that the fact, that IPA is revised and formulated time and again in order to accommodate the speech sounds of the different languages and should not be forgotten during the researches of this type. There are sounds which bring contrast among the different languages in the world. These do not reflect the abilities of the production of human sounds, many of them are present in their allophonic form (Simpson, 2014).

The Levenshtein distance (LD) constitutes the framework of this study and a procedure used to measure the distance present between strings. This method works through insertions, deletions, and substitutions to determine the similarity index. The difference between the strings depends on the number of the Levenshtein distance. The greater number of Levenshtein distance indicates that both strings have maximum differences. This algorithm was devised by a Russian Scientist Vladimir Levenshtein in 1965. Following example may well explain this algorithm the Levenshtein distance may also be analyzed, as "kitten" and "sitting" have a difference of three strings.
1) Kitten $\rightarrow$ sitten (substitution of "s" for "k")
2) sitten $\rightarrow$ sittin (substitution of "I" for "e")
3) sittin $\rightarrow$ sitting (insertion of " $g$ " at the end). 


\subsection{Objectives}

The major goal of this study is computing the similarity level percentage between the phonemic systems of English and Punjabi, by using the Levenshtein algorithm. It will also yield a percentage of differences.

\subsection{Research Questions}

1) What is the similarity index, between the consonants of English and Punjabi?

2) What is the index of difference, between the consonants of English and Punjabi?

Two linguistic systems that have a similarity index of more than $85 \%$ are generally considered to be the dialects of the same language (Maldonado García \& Borges de Souza, 2014). In light of this research outcome, the similarity index percentage between English and Punjabi should be considerably lower than $85 \%$ due to their genetic differences.

\section{Methodology}

A mixed methodology i.e., quantitative and qualitative technique is used to analyze the phonemic differences and similarities. The phonetic inventories of both languages are used as data.

The nature of this study is expository and it is designed to calculate the index of the phonetic similarity and differences between English and Punjabi spoken in the various parts of the globe. The present research is limited to the consonant sounds only.

\subsection{Framework}

The framework for the present research is the comparison through the application of the Levenshtein algorithm which will provide an accurate ratio of phonemic similarity and differences index between both linguistic systems through the comparison of their sounds (through their transcription into IPA). The framework has already been used in different studies (Maldonado García \& Borges de Souza, 2014; Heeringa, 2004; Sanders \& Chin, 2009).

\subsection{Instrument}

The instrument of the research is the phonetic inventories of English and Punjabi languages. The English phonetic inventory of Roach (2015) and the Punjabi phonemic inventory by Karamat (2015) was mapped on tables for the comparative analysis through the framework of the Levenshtein algorithm.

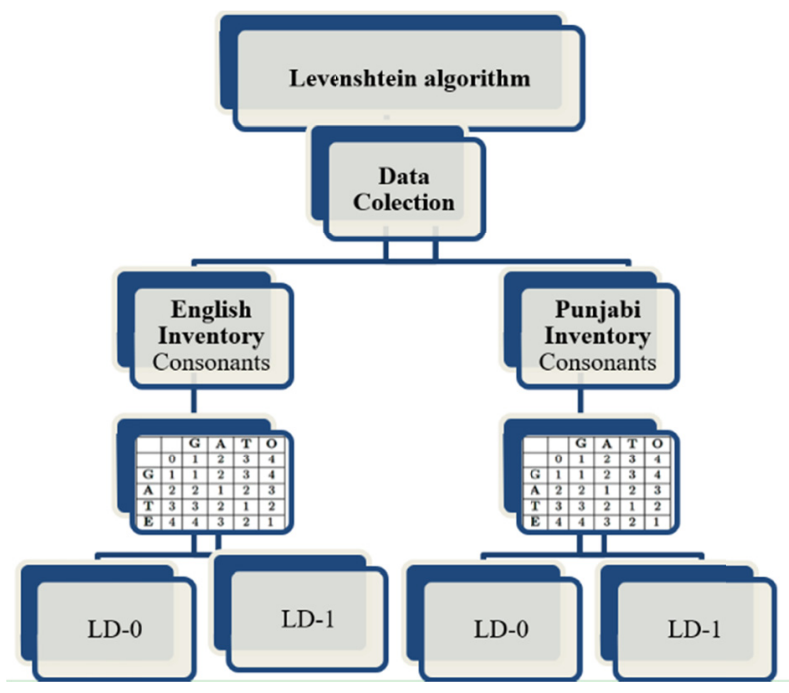

Figure 3. Methodology of the study 


\subsection{Limitations of the Research}

The current research is delimited only to the comparison of the consonant sounds of English and Punjabi. The similarities and differences are assessed and calculated numerically. The vowel sounds will be compared in another publication.

\section{Data Analysis}

The data for the recent research have been analysed in term of the number of distances measured by the Levenshtein Algorithm in tabulated form. The analysis of the sounds was conducted, which provides the number of differences between the two sounds. Kessler, in 1995, applied this algorithm to bring out the ratio of differences and similarities among the strings of the two dialects of Irish. Through the application of the Levenshtein algorithm, he was able to measure the distance between the two. In this study, the Levenshtein distance is calculated phonemically between the phonetic inventories of the consonants of English and Punjabi.

\subsection{Measuring Phonemic Distance}

This well-recognized method was used by Ethnologue and Automated Similarity Judgment Program (ASJP) to determine language relations through genetics and also by Maldonado García (2014) to determine the similarity index between Portuguese and English. In this study, the Levenshtein distance is calculated from a phonemic perspective between English and Punjabi.

\subsection{Sounds with Zero Distance (Distance 0 or $100 \%$ Similarity)}

English and Punjabi are the two different languages which belong to two different families of languages. Yet they present phonemic similarity between them. Both of the languages may have less structural overlap, which renders minimum mutual intelligibility. The sounds which have zero distance are given in the following table:

Table 1. Phoneme in English and Punjabi with zero distance

\begin{tabular}{llll}
\hline Sr. No. & Punjabi & English & Levenshtein Distance \\
\hline 1$)$ & $/ \pi /$ & $/ \pi /$ & 0 \\
$2)$ & $/ \beta /$ & $/ \beta /$ & 0 \\
$3)$ & $/ \tau /$ & $/ \tau /$ & 0 \\
$4)$ & $/ \delta /$ & $/ \delta /$ & 0 \\
$5)$ & $/ \kappa /$ & $/ \kappa /$ & 0 \\
$6)$ & $/ \gamma /$ & $/ \gamma /$ & 0 \\
$7)$ & $/ \phi /$ & $/ \phi /$ & 0 \\
$8)$ & $/ \Phi /$ & $/ \Phi /$ & 0 \\
$9)$ & $/ \sigma /$ & $/ \sigma /$ & 0 \\
$10)$ & $/ \zeta /$ & $/ \zeta /$ & 0 \\
$11)$ & $/ \Sigma /$ & $/ \Sigma /$ & 0 \\
$12)$ & $/ \eta /$ & $/ \eta /$ & 0 \\
$13)$ & $/ \mu /$ & $/ \mu /$ & 0 \\
$14)$ & $/ v /$ & $/ v /$ & 0 \\
$15)$ & $/ \mathrm{N} /$ & $/ \mathrm{N} /$ & 0 \\
$16)$ & $/ \rho /$ & $/ \rho /$ & 0 \\
$17)$ & $/ \lambda /$ & $/ \lambda /$ & 0 \\
$18)$ & $/ \varphi /$ & $/ \varphi /$ & 0 \\
$19)$ & $/ \tau \Sigma /$ & $/ \tau \Sigma /$ & 0 \\
$20)$ & $/ \delta \mathrm{Z} /$ & $/ \delta \mathrm{Z} /$ & 0 \\
\hline
\end{tabular}

In light of the above table, 20 consonant sounds have zero distance phonemically between them as per the Levenshtein Algorithm. This means English and Punjabi have twenty common consonants.

\subsection{Consonant Sounds with Distance 1. Sounds That Are Different in both Languages, Punjabi and English}

Levenshtein algorithm calculated that 20 consonant sounds in English and Punjabi have zero difference and maximum similarity between them, but some sounds have a phonetic difference as well. The difference in number will render the ratio of difference. The consonant sounds which have 01 distance are given in the following table: 
Table 2. Phonemes in English and Punjabi with distance of 1

\begin{tabular}{llll}
\hline Sr. No. & Punjabi & English & Levenshtein Distance \\
\hline 1$)$ & $/ \pi^{\eta} /$ & - & 1 \\
$2)$ & $/ \tau /$ & - & 1 \\
$3)$ & $/ \tau^{\eta} /$ & $/ \mathrm{T} /$ & 1 \\
$4)$ & $/ \delta /$ & $\Delta$ & 1 \\
$5)$ & $/ \tau^{\eta} /$ & - & 1 \\
$6)$ & $/ \kappa^{\eta} /$ & - & 1 \\
$7)$ & $/ \tau \Sigma^{\mathrm{h} /}$ & - & 1 \\
$8)$ & - & $/ \mathrm{Z} /$ & 1 \\
$9)$ & $/ \Xi /$ & - & 1 \\
$10)$ & $\mathrm{N}$ & - & 1 \\
$11)$ & $/ \Gamma /$ & - & 1 \\
$12)$ & $/ 4 /$ & - & 1 \\
$13)$ & $/ \lambda /$ & - & 1 \\
$14)$ & - & $/ \omega /$ & 1 \\
\hline
\end{tabular}

The comparison resulted in that $/ \pi^{\eta} /, / \tau /, / \tau^{\eta} /, / \kappa^{\eta} /, / \tau \Sigma^{\mathrm{h}} /, / \Xi /, / \mathrm{N} /, / \Gamma /, / 4 /, / \lambda \bar{\tau} / \mathrm{Z} /, / \omega /, / \delta /, / \Delta /$ are the fourteen sounds which have 1 distance phonemically between them as per the Levenshtein Algorithm. This means that 14 sounds are completely different in both phonetic systems. Among these 14 sounds $/ \pi^{\eta} /, / \tau /, / \tau^{\eta} /, / \kappa^{\eta} /, / \tau \sum^{\mathrm{h}} /, / \Xi /, / \mathrm{N} /, / \Gamma /, / 4 /, / \lambda /$ are the sounds which are found only in Punjabi language and $/ Z /, / \omega$ are found only in the English language. Whereas, $/ \delta /, / \Delta /$ are the sounds which have different symbols in both languages but have the same pronunciation.

\subsection{Tabularized Comparison and Contrast of the Consonants of both Dialects}

The distance measured above shows that the sounds with distance of zero are considered similar sounds in the inventories. While the sounds that have difference of one are considered different sounds used in the inventories. The table below the number of similar sounds and the percentage of similarity between two dialects:

Table 3. Similarity index between English and Punjabi Consonants

\begin{tabular}{ll}
\hline Dialectical Sounds & English and Punjabi \\
\hline Total similar consonant sounds & 20 \\
Total consonantal phonemic similarity & $56.25 \%$ \\
\hline
\end{tabular}

In term of differences between the sounds of both the dialects, the following table is self-explanatory:

Table 4. Index of differences between English and Punjabi consonants

\begin{tabular}{ll}
\hline Dialectical Sounds & English and Punjabi \\
\hline Total no of different consonant sounds & 14 \\
Total consonantal phonemic difference & $43.75 \%$ \\
\hline
\end{tabular}

The analysis shows that English and Punjabi have a 56.25\% phonemic similarity index. On the other hand, their distance in term of the ratio is $43.75 \%$. The index of similarity and difference rendered in term of ratio shows that English and Punjabi are two different languages. Both these languages have less similarity and more differences. 


\section{Levenshtein Algorithm}

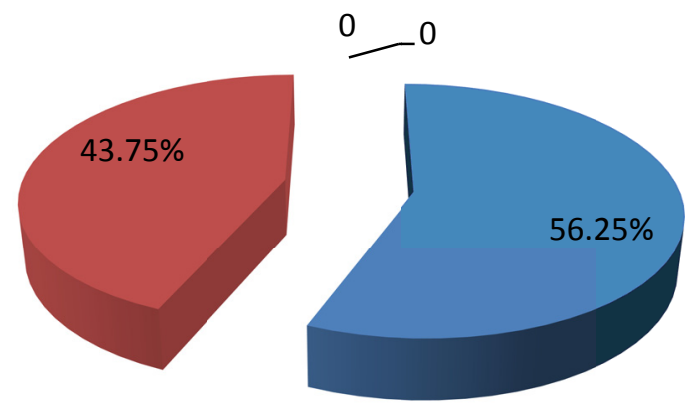

Similarity

Difference

Figure 4. Index of difference between the consonants of English and Punjabi

The above pie graph shows the ratio of difference and similarity index between English and Punjabi.

\section{Discussion}

The present research intended to calculate the phonemic similarities and differences between these two languages. In this regard, the analysis was performed after obtaining the data from the inventories of both these languages. It was found that $/ \pi / / \beta / / \tau / / \delta / / \kappa /, / \gamma /, / \phi /, / \bar{\sigma} /, / \sigma /, / \zeta /, / \Sigma /, / \eta /, / \mu /, / \nu /, / \mathrm{N} /, / \rho /, / \lambda /, / \varphi /, / \tau \Sigma /, / \delta \mathrm{Z} /$ are the twenty consonant sounds of English, which are also used in the Punjabi language. All these sounds have the same manner and places of their articulation in both the linguistic systems. The sounds $/ \pi / \beta / / \tau / / \delta / / \kappa /, / \gamma /$, and $/ \rho /$ are found to be plosives in English as well as Punjabi inventory. $\tau \eta \varepsilon \sigma o v v \delta \sigma / \phi /, / \varpi /, / \sigma /, / \zeta /, / \Sigma /, / \eta /$ are found to be fricatives in both inventories. The nasal sound found in English and Punjabi are $/ \mu /, / \nu /, / N / . I v \tau \varepsilon \rho \mu$ o $\phi \alpha \pi \pi \rho \circ \xi 1 \mu \alpha \nu \tau \sigma / \lambda /, / \varphi /$ sounds are found to be approximants in both inventories. The $/ \tau \Sigma /, / \delta \mathrm{Z} /$ sounds are to be found affricates in English. In this way, 20 consonant sounds have maximum similarity among them both in English and Punjabi languages. Both of this language share the symbols of these sounds. This can assist the learners of the English language to learn sounds faster and better since these are common between both languages. On the other hand, $/ \pi^{\eta} /, / \tau /, / \tau^{\eta} /, / \kappa^{\eta} /, / \tau \Sigma^{\mathrm{h}} /, / \Xi /, / \mathrm{N} /, / \Gamma /, / 4 /, / \lambda \bar{T}$ are the sounds which are not found in English inventory, these are present only in Punjabi inventory. Whereas, $/ \mathrm{Z} / \mathrm{s} /$ are the sounds which are found only in the English language and nor in Punjabi. On the other hand, $/ \delta /$ is found to be plosive in Punjabi and $/ \Delta /$ is fricative in the English language. Both of these sounds are represented by the different symbols but have the same pronunciation. In this way, all these 14 sounds are found to be different in both languages. These sounds were different from one another and have a distance of 1 calculated by the Levenshtein algorithm. The sounds which have zero measurements and 1 are tabulated separately.

\section{Conclusion}

In the light of the above discussion, it can be concluded there are 24 consonant sounds in the English language and 32 consonants sounds in Punjabi. Among these 56 consonants sounds found in both English and Punjabi languages, 20 consonants sounds are used in both languages, which share the same manner and places of articulation. However, there are 14 sounds in both the languages which are different in term of their manner and places of articulation. Thus, the similarity level (as per the Levenshtein algorithm), between the consonant sounds of these two languages is $56.25 \%$ and the distance between these languages is $43.75 \%$. These twenty consonant sounds are used by the speakers of both English and Punjabi languages. Whereas, the rest of the 14 sounds are used differently by the speakers of these languages. As these two linguistics systems have a 56.25\% similarity index, the outcome of this research, testifies to the assumption, that a similarity percentage higher than $85 \%$ between two linguistic systems, generally indicates that one of the systems is likely a dialect of the language with which it is being compared (Maldonado García \& Borges de Souza, 2014). The present research will assist native Punjabi speakers in terms of learning English as their second language.

\section{References}

Algeo, J., \& Butcher, C. A. (2013). The origins and development of the English language. Cengage Learning. 
Bhatia, T. (1993). Punjabi: Acognitive-descriptive grammar. New York: Routledge.

Brinton, L., \& Traugott, E. (2005). Lexicalization and language change. Cambridge: Cambridge University Press. https://doi.org/10.1017/CBO9780511615962

Campbell, G. (1991). Compendium of the World's Languages. London: Routledge.

Chen, N., Tam, S., Shen, W., \& Campbell, J. (2014). Characterizing phonetic transformations and acoustic differences across English dialects. IEEE/ACM Transactions on Audio, Speech, and Language Processing, 22(1), 110-124. https://doi.org/10.1109/TASLP.2013.2285482

CIA Factbook. (2019). Retrieved from https://www.cia.gov/library/publications/the-world-factbook/geos/in.html

Clark, J., \& Yallop, C. (2011). An introduction to phonetics and phonology. Massachusetts: Blackwell Publishing.

Crystal, D. (2012). English as a global language. Cambridge: Cambridge University press. https://doi.org/10.1017/CBO9781139196970

Dalton-Puffer, C. (2011). Content and language integrated learning: From practice to principles? Annual Review of Applied Linguistics, 31, 182-204. https://doi.org/10.1017/S0267190511000092

Dua, M., Aggarwal, R., Kadyan, V., \& Dua, S. (2012). Punjabi automatic speech recognition using HTK. International Journal of Computer Science Issues, 9(4),1694-1814.

Dufour, F. (2017). Exploring the possibilities for the emergence of a single and global native language. Philosophy of Language E-Journal, 10(29). https://doi.org/10.2139/ssrn.3068406

Ethnologue. (2016). Retrieved from https://www.ethnologue.com/language/pnb

Ethnologue. (2019). Retrieved from https://www.ethnologue.com/language/pnb

Ghai, W., \& Singh, N. (2012). Analysis of automatic speech recognition systems for indo-aryan languages: Punjabi a case study. International Journal of Software and Computer Engineering, 2(1), 379-385.

Ghai, W., \& Singh, N. (2013). Phone Based Acoustic Modeling for Automatic Speech Recognition for the Punjabi Language. Journal of Speech Sciences, 3, 69-83.

Giegerich, H. J. (1992). English phonology: An introduction. Cambridge University Press. https://doi.org/10.1017/CBO9781139166126

Gimson, A. G. (1980). An Introduction to the Pronunciation of English (3rd ed.). Australia: Edward Arnold Pty. Ltd.

Gooskens, C., \& Schneider, C. (2016). Testing mutual intelligibility between closely related languages in an oral society. Language Documentation \& Conservation, 10, 278-305.

Goyal, V., \& Lehal, G. (2008). Comparative Study of Hindi and Punjabi Language Scripts. Research Gate.

Gregova, R. (2010). A Comparative Analysis of Consonant Clusters in English and in Slovak. Bulletin of the Transilvania University of Brasov, 3(52).

Grierson, A. (1916). Linguistic Survey of India. Delhi: Motilal Banarsidass.

Hajek, J., \& Maeda, S. (2000). Investigating universals of sound change: The effect of vowel height and duration on the development of distinctive nasalization. Cambridge University Press.

Hardcastle, W. J., \& Beck, J. M. (2005). A Figure of Speech. New Jersy: Lawrence Erlbaum.

Hastuti, S. T. B. (2017). A study of English tutors' code switching in training the PGSD USD English Club. Doctoral dissertation, SANATA DHARMA UNIVERSITY.

Heeringa, W. J. (2004). Measuring dialect pronunciation differences using Levenshtein distance. Citeseer. https://doi.org/10.1080/09296170802514138

Hogg, R. M., Burchfield, R. W., Blake, N. F., Romaine, S., Lass, R., \& Algeo, J. (1992). The Cambridge history of the English language: The beginnings to 1066 (R. M. Hogg Ed.). Cambridge: Cambridge University Press. https://doi.org/10.1017/CHOL9780521264747

Javed, F. (2013). Arabic and English phonetics: A comparative study. The Criterion: An International Journal in English, 4(4).

Jenkins, J. (2009). English as a lingua franca: Interpretations and attitudes. World Englishes, 28(2), 200-207. https://doi.org/10.1111/j.1467-971X.2009.01582.x 
Karamat, N. (2001). The phonemic inventory of Punjabi. Annual Student Report, 179-183.

Kaur, E. J., Nidhi, E., \& Kaur, M. R. (2012). Issues Involved in Speech to Text Conversion. International Journal of Computational Engineering, 512-515

Kessler, B. (1995, March). Computational dialectology in Irish Gaelic (pp. 60-66). In Proceedings of the Seventh Conference on European Chapter of the Association for Computational Linguistics. Morgan Kaufmann Publishers Inc. https://doi.org/10.3115/976973.976983

Levenshtein, V. I. (1965). Binary codes capable of correcting, deletion, insertions Andreversals. Cybernetics and Control Theory, 10, 707-710.

Maddieson, I. (1984). Patterns of sounds. Cambridge university press. https://doi.org/10.1017/CBO9780511753459

Maldonado García, M. I. (2018). A corpus based quantitative survey of the etymological elements in the basic vocabulary of Urdu language. Almas, 20, XI-XXIV.

Maldonado García, M. I., \& Borges De Souza, A. (2014). Lexical similarity level between English and Portuguese. Grassroots, 49(1), 203-218.

Masica, P. (1993). The Indo-Aryan Languages. New York: Cambridge University Press.

Myers-Scotton, C. (2005). Multiple Voices: An Introduction to Bilingualism. Oxford: Wiley-Blackwell.

Nunan, D. (2003). The impact of English as a global language on educational policies and practices in the Asia - Pacific Region. TESOL Quarterly, 37(4), 589-613. https://doi.org/10.2307/3588214

Purnell, T., Idsardi, W., \& Baugh, J. (1999). Perceptual and phonetic experiments on American English dialect identification. Journal of Language and Social Psychology, 18(1), 10-30. https://doi.org/10.1177/0261927X99018001002

Pyles, Thomas and John Algeo (1993). Origins and development of the English language. 4th edition. New York: Harcourt, Brace, Jovanovich.

Rahman, G. (2016). A Comparative Study of Pashto and English Consonants. Pashto, 45, 11-27.

Roach, P. (2010). English phonetics and phonology: A practical course (4th ed.). Ernst KlettSprachen.

Sanders, N. C., \& Chin, S. B. (2009). Phonological Distance Measures*. Journal of Quantitative Linguistics, 16(1), 96-114.

Schepens, J., Dijkstra, T., Grootjen, F., \& Heuven, W. J. B. (2013). Cross-language distributions of high frequency and phonetically similar cognates. PloS One, 8(5). https://doi.org/10.1371/journal.pone.0063006

Shackle, C. (1970). Punjabi in Lahore. Modern Asian Studies, 4(03), 239. https://doi.org/10.1017/S0026749X00011926

Simpson, A. P. (2014). Ejectives in English and German-linguistic, sociophonetic, interactional, epiphenomenal? In C. Chiara \& C. Silvia (Eds.), Advances in sociophonetics. Amsterdam: Benjamins. https://doi.org/10.1075/silv.15.07sim

Sundara, M. (2005). Acoustic-phonetics of coronal stops: A cross-language study of Canadian English and Canadian French. The Journal of the Acoustical Society of America, 118(2), 1026-1037. https://doi.org/10.1121/1.1953270

Temple, R. C. (1883). Punjabi notes and queries (ms.).

Williams, J. M. (1986). Origins of the English language. Simon and Schuster.

Zahid, S. (2010). An Acoustic Analysis of Vowel Nasalization in Punjabi Speakers' Production of English in Pakistan. Faisalabad, Pakistan: Government College University, Faisalabad, Pakistan.

\section{Copyrights}

Copyright for this article is retained by the author, with first publication rights granted to the journal.

This is an open-access article distributed under the terms and conditions of the Creative Commons Attribution license (http://creativecommons.org/licenses/by/4.0/). 